\title{
VALUE-SENSITIVE DESIGN FOR INDIGENOUS PEOPLE OF OAXACA, MEXICO
}

\author{
D.E. SANTOS-REYES ${ }^{1}$ \& A.J. MENDOZA-JASSO ${ }^{2}$ \\ ${ }^{1}$ I'chi Research and Engineering, Mexico. \\ ${ }^{2}$ Industrial Engineering Department, Mixteca University of Technology (UTM), Mexico.
}

\begin{abstract}
This paper describes an ongoing research and development project on engineering value-sensitive design for indigenous people called Mixtecs, and for wider segments of the system of focus, in Oaxaca, Mexico. Although the Mixtec people have creatively maintained their fundamental way of doing things from the pre-Hispanic past to the present day, they are being influenced by a new wave of conflicting factors. These factors, namely economical, technological, environmental and global issues, threaten the survival of the Mixtecs' approach. In addition to these issues, the fast growing rate of crime also impedes growth. A crucial way to understand the current Mixtecan situation is to use complex systems thinking to address the core issues that inhibit growth and subsequently to implement action. It is believed here that there are essential issues of value and these have implications for engineering design. Engineering value-sensitive design may have important implications in addressing the Mixtec people's situation without compromising their values, culture and traditions.

Keywords: innovation, design, sustainability, crime, value.
\end{abstract}

\section{INTRODUCTION}

The Mixtecs have creatively maintained their fundamental way of doing things from the pre-Hispanic past to the present day. However, they are being influenced by a new wave of conflicting factors over the last few decades. These include environmental, economical, technological and global issues that threaten their survival approach. In addition to these, the fast growth of crime rate is also a major obstacle for motivating growth [1]. Complex systems approach [2,3] is used as the means to develop an understanding of the current situation of the Mixtecs. Cleary, there are essential issues of value and these have implications for engineering design. This demands the consideration of all the conflicting factors that impend the existence of the way of these indigenous people. In other words, engineering value-sensitive design may have important implications in addressing the Mixtecan economic and technological advance without compromising their values, culture and traditions. The relevance of innovation, engineering and value-sensitive design, as well as the disruption of the Mixtecs' way, are discussed in Section 2. Section 3 presents the current situation and the research approach adopted for addressing the problem-solving process. Section 4 highlights the main focus of the authors' efforts to address the Mixtecs' situation and, finally, some relevant conclusions and further work are presented in Section 5.

\section{INNOVATION, ENGINEERING AND VALUE-SENSITIVE DESIGN}

\subsection{Responsible innovation}

Innovation, according to Schumpeter's classical concept [4], involves the creation of new and improved products and processes, the use of existing technology into new applications, the discovery of new resources and the opening of new market segments. It is widely recognised nowadays that this is a world characterised by continuous and fast development of new technologies. Technology is, however, never value neutral [5]. When new technologies emerge 
and diffuse, there is a presumption that there will be changes in both nature and society. These changes are the result of a dynamic process of continuous conjunction between technological change and social change.

It seems that there are two ways to advance an understanding of how technology innovation is affecting and will affect the future. First, the positive impact of the innovation on economic growth, industrial productivity and organisations' competitiveness has been extensively acknowledged and documented over the last few years. The other way is that there has been a rapidly developing interest in issues such as sustainable design [6,7] and renewable energy technology [8]. Furthermore, recent debate has focused on the questions of responsible innovation (RI) [9]. The development and adoption of new technologies enable changes in social organisations and values. This is done by creating new possibilities and increasing the number of options available to people [10]. This requires creativity to address an increasing number of values, such as privacy, security, inclusion, sustainability, democracy, safety, accountability, to mention a few. This is the concern of RI. It is about developing technology and designing products that integrate customers/ users' values.

\subsection{Disruption of the Mixtecs' way (I'chi)}

Recent studies suggest that the Mixtecs can be classified as native Americans that arose from an ancestral Asian population which migrated to the Americas more than 21,000 years ago [11]. The country of these indigenous people lies within the states of Guerrero, Puebla and chiefly in Oaxaca. As shown in Fig. 1, the territory occupied by the Mixtecs extends eastwards from the Pacific coast of Mexico into the high mountain country of the interior. In Oaxaca, they occupy a province known as the Mixtec region, which in turn consists of highland, lowland and coastal sub-regions.

Archaeological, ethnographical and anthropological studies suggest that pre-Columbus Mextecs had the state-of-the-art technology to deal with survival. They grew their own food and relied on rain to irrigate their soil. Agricultural techniques helped to protect, conserve and nourish the cultivatable soil. Small-scale irrigation systems such as wells, dams and canals were used to divert seasonal flood-water to irrigate fields in the piedmont. Food production revolved around the milpa, invented and diffused more than 9,000 years ago. This system was, and still is today, a response of not only the Mixtecs, but of all indigenous people of Mexico, to environmental, social, economic and cultural factors. The milpa consisting mainly of corn, squash and bean plants represents a point in evolutionary

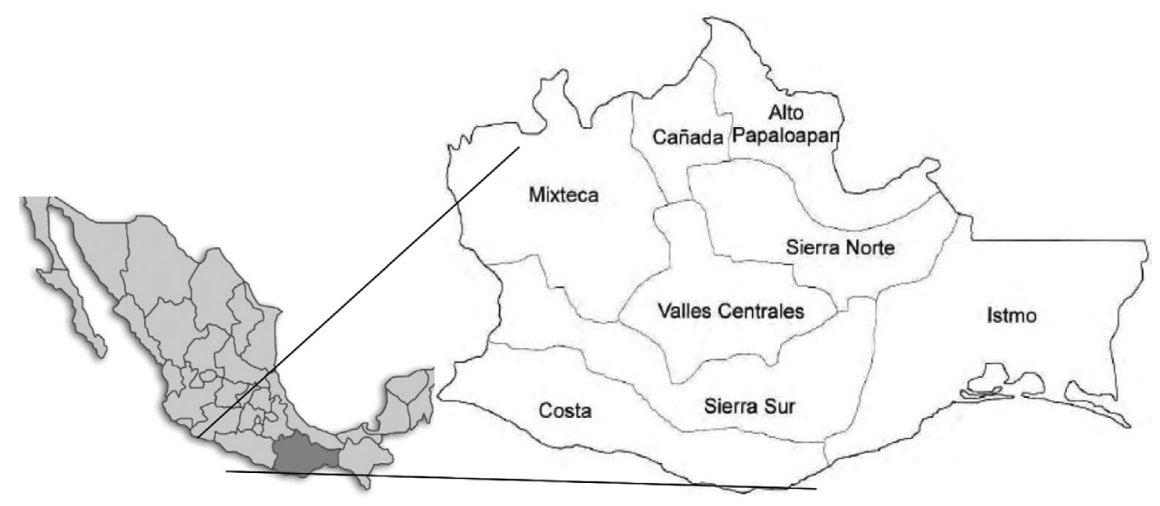

Figure 1: Mixteca region, Oaxaca, Mexico. 
and adaptive complex processes. Along with this technological progress, corn tortilla and related processing technology were developed throughout Mexico. A tortilla is a multifunction soft, thin, flat, circular-shaped bread made from finely ground corn flour. This core platform technology further developed and diversified into a great number of new products. Today, this is the main constituent of the Mexican diet. In addition to the milpa, a wide variety of other sources of sustenance included plants, such as the prickly pear fruit from the nopal cactus, avocados, cacao, chilli, green tomato, maguey and ceremonial plants such as native tobacco. Mixtecs also possessed the skills for freerange growing turkeys. In parallel with other cultures of the world, they discovered death and since then they invented tools for killing. In relation to the provision of food, the people of the rain hunted edible wildlife.

Indigenous inhabitants of the Mixtec region had very well established designs and production systems of domestic artefacts [12]. They have designed and produced crafts such as pottery, lithic, baskets, amongst other products. Mixtecan technologies were closely linked to the natural world. They wore modest clothing, usually made of 'maguey' fibre, and lived in houses made from thatch and wattle-and-daub, sometimes with stone or adobe foundations. Similarly, herbal medicine had been used within the Mixtecan culture to prevent and treat diseases. This systemic approach to health sourced the healing materials mostly from within their own geographical location. The main sources of energy were solar, biomass and oil. Although the amount of produced energy was small and costly, they knew how to convert one form of energy into another form to support production of sustenance.

When they transformed from nomad to sedentary, Mixtecs developed sophisticated architectural systems, such as pyramids and squares. Usually, these systems incorporated visual art features, such as carved stones, paintings and figurative ceramics. Similarly, they had a sophisticated approach to communicate: a language of their own, including pictorial texts. The latter disrupted by the conquistador, whilst the former is still spoken, but is evaporating slowly. As discussed elsewhere [13], the graphical communication evolved from incidental petroglyphs and rock paintings to a sophisticated system of pictographic manuscripts in the form of screen-fold books, known as codex, of deerskin or paper, and painted cotton cloth.

\subsection{Value-sensitive design}

Under the influence of a barbaric invasion, issues beyond their control, such as religious, social, economic, technological and health changes drove Mixtecs to adopt creatively some elements of the European culture without disrupting totally their own way. Anyone who has actually observed the Mixtec people will realise that the fundamental way of doing things continues to exist from the preHispanic past to the present day. Recent research on the present day of indigenous people of Oaxaca agrees with this statement. However, the people of the rain, cloud or heat, as they are known in the original language, are being influenced by a new wave of conflicting factors namely environmental, economical, technological, criminal and global issues. This ancient civilisation has not been conquered from without but is being destroyed by itself from within. This demands the consideration of all the conflicting factors that threaten the existence of the way of the Mixtecs. However, the often conflicting, sustaining self-identity and adopting globalisation issues is not the only tension Mixtecs encounter. It is believed here that there are essential issues of value. Furthermore, these concerns have implications for design. In other words, engineering value-sensitive design may have important implications in addressing the conflicting issues of the survival of the Mixtecs. What follows outlines the approach to these issues. 


\section{THE MIXTECS' CURRENT SITUATION}

\subsection{The approach}

Figure 2 unfolds the complexity of the system of focus. It intends to portray the Mixtecs as a whole, a complex adaptive system, instead of as a sum of self-contained people and culture. The approach seeks to understand better how this totality evolves through the millennia. A crucial way to exhibit the current Mixtecan situation is to think from complex systems thinking. This is, to think of Mixtec people as inextricably involved with other people, near and far, in a global community interaction. It attempts to frame the current situation in order to focus thinking on the very core issues that give rise to policy and decision makers, the Mixtecs themselves, and researchers to think, and subsequently to implement action. The purpose is to frame the factors, such as ecological, physical and technological, to understand the observable rhythms and structures of the Mixtecs' survival. Additionally, these factors describe interactions with geography, culture and socio-technical circumstances. The use of this systemic description of the problem situation and any associated remedy of this gives rise to new considerations that have previously been unnoticed or deliberately disregarded in favour of the established status quo. It is customary of public problem solvers, in the guise of delivering better solutions to indigenous people's situations, to overlook the systemic nature of the problem, which translates into problem creation. This very consideration of neglecting the complexity of the indigenous people's situations should now be brought onto the focus point in order to eradicate this reductionist action.

\subsection{The situation}

\subsubsection{Mixtecs and the World}

It seems that a defining feature of the Mixtecs' unease over the last few decades has been globalisation. The interconnection of world economies has driven global trade, consumerism, technology and knowledge flows that are profoundly influencing Mixtecs' way. This is a great tension between the Mixtec people and the world people. The Mixtec people should be able to maintain an independent existence within a global world. As the Mexican, and the world, population inexorably increase, the natural environment continues to deteriorate and the gap between the rich and the poor increases, the people of the rain face the dilemma of whether to keep favouring quality of life or shift to standard of living above all other values. Clearly, it is important for the Mixtec people to value and improve themselves, and it is equally important for the Mixtecs to contribute in the improvement of the Mexican society within the global community.

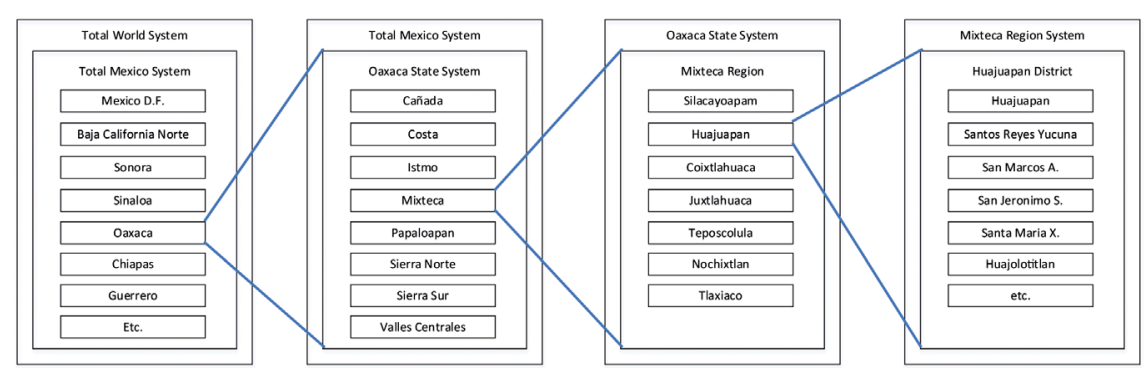

Figure 2: The Mixtecs recursive levels of being. 


\subsubsection{Cooperation and competition}

The current global economic interconnectedness is unparalleled and is becoming more pronounced with each passing year. Globalisation has increased competition not only between companies that contend in the same market place but also between countries and individuals. As the Mexican nation builds into a global economy, successful competition is paramount. On the other hand, it is well known that ancient civilisations, including Mixtecs, are highly skilled at working together towards the same end. In this sense, Mixtecs can contribute to finding balance between competition and cooperation to enable growth.

\subsubsection{Old and new}

Information and communication technology is homogenising the world people's cultures. Clearly, the world people benefit from this commonality. However, the new is replacing the delightful ancient culture or way of the Mixtecs, for example. There is the need to recognise the Mixtecs' old way that makes it special.

\subsubsection{Growth and decay}

Forerunners of the modern Mixtecs designed and developed tools to enable them to hunt, gather and later grow food. They crafted stone cutting tools and arrow-heads amongst other inventions. Later, they further developed and diversified these technologies. However, it seems that their ability to innovate was halted by the process of the Spanish invasion. Now, Mixtecs are required to disrupt this decay process by design in order to stimulate growth.

\section{ENGINEERING VALUE-SENSITIVE DESIGN}

\subsection{The engineering problem}

Survival is the consequence of a number of factors and long periods of evolution. As emphasised above, Mixtecs are involved in highly complex environments, as shown in Fig. 2. They must adapt not only to their harsh local environment but also to the chaotic global environment, whilst retaining their identity. Figure 3 shows a simplified proposed system. The fast analysis system technique, as part of the value analysis, is a rigorous process for designing engineering systems [14]. It is used here for designing complex social systems. The two vertical lines shown in Fig. 3 define the scope

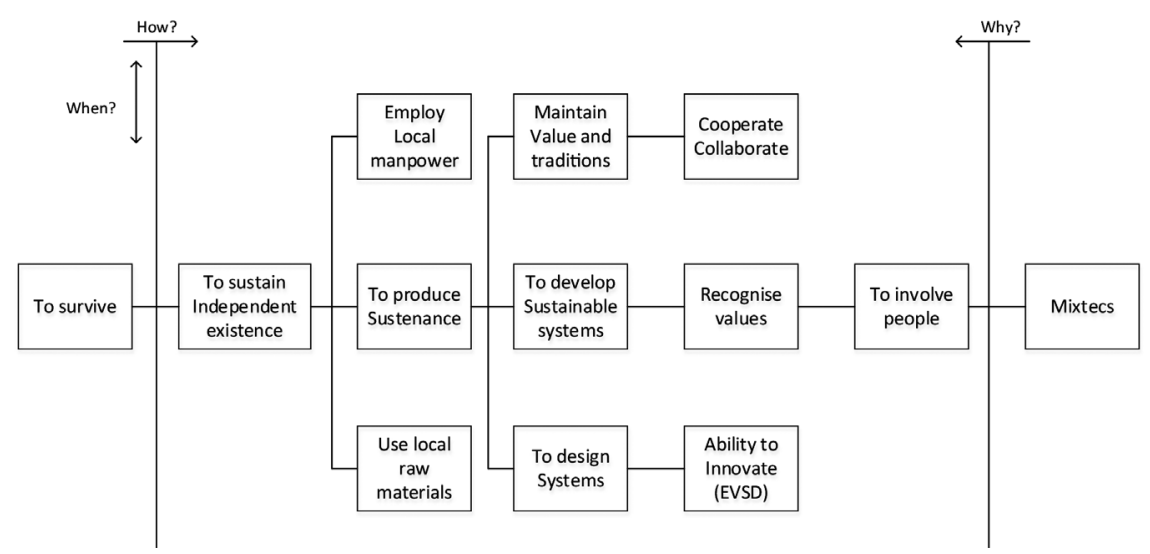

Figure 3: Function analysis system technique for the Mixtecs' survival. 
of the design problem. The survival of the Mixtecs is the highest level function and it is the consequence of the basic functions, as shown to the immediate right of the left scope line. To sustain an independent existence is a higher level function that represents our proposed approach for the survival of the Mixtecs. The other functions represent the means to achieve this higher level function. These functions were established by the how-why logic. How do Mixtecs sustain an independent existence? It seems that the answer is by producing their own sustenance. Why do Mixtecs produce their own sustenance? Because they need to sustain an independent existence. The functions shown in Fig. 3 were arranged by comparing each other using the how-why logic.

The practice of engineering design is the means by which the authors intend to improve the Mixtecs' current situation in a number of ways, including systems such as agricultural or construction. In particular, value-sensitive design is used to facilitate our ability to innovate engineering systems (Fig. 3). As society strongly believes that medical practice is likely to make one into a healthier person, engineering too has the capability for moral and value formation. However, engineering process is not automatic any more than it is automatic for medical practice. As value and engineering design are closely related, to engage both requires the ability to innovate and to participate in practical reasoning. To achieve an independent existence, Mixtecs must develop and produce their own sustenance and services in the same way they used to do in the pre-Spanish era. The following section highlights some relevant development projects that intend to comply with the function: to develop sustainable systems shown in Fig. 3.

\subsection{Development projects}

To meet the demand on the Mixtecs' performance, novel solutions and concepts are being investigated and developed by the authors. A coherent analysis and synthesis of systems, such as energy sources and conversion, engineering food products and processes, architectural systems and agricultural systems, is paramount to ensure success. As depicted in Fig. 4, integration of ingenuity, science and technology is the core of our teleological mechanism of novelty. In addition, the optimum performance of systems can only be designed by using advanced engineering practice. Various engineering systems are under development. These include machines to process round-shaped native natural materials, such as reed, sticks and otate. This may increase significantly the productivity of the production of baskets of diverse shape and size, which are traditional Mixtec products. Regarding architectural systems, a system to dampen earthquake vibration has been conceived, as reported elsewhere [15], and a demonstration house will be built over the next 2 years.

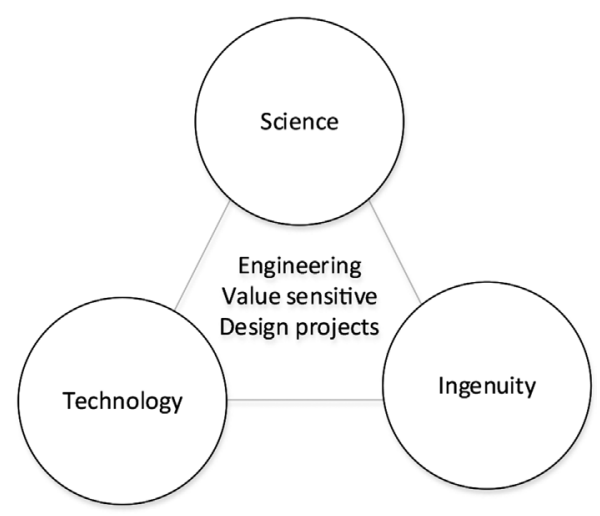

Figure 4: I'chi approach to research and engineering projects. 


\section{CONCLUSIONS}

This article argued that the indigenous people of Oaxaca, Mexico, called Mixtecs are experiencing a new wave of factors that affect their growth. The authors, with the hope of improving this situation, use RI, in particular, value-sensitive design. A number of development projects are underway, which will be implemented in the small village of Santos Reyes Yucuna, Oaxaca, Mexico, over the next few years. The successful implementation and outcomes of these projects, by providing the knowledge and skills to this people, may go some way to reducing both the rate of emigration and poverty, including the likelihood of their involvement in crime - be that as criminal or victim.

\section{REFERENCES}

[1] Santos-Reyes, D.E. \& Santos-Reyes, J.R., Patterns of temporal diffusion of crime in Mexico. International Journal of Safety and Security Engineering, 2(2012), pp. 54-68, 2012. doi: http://dx.doi.org/10.2495/safe-v2-n1-54-68

[2] Beer, S., Brain of the Firm, John Wiley \& Sons: Chichester, 1995.

[3] Rouse, W.B., Health care as a complex adaptive system: implications for design and management. The Bridge, 38(1), pp. 17-25, 2008.

[4] Schumpeter, J.A., Business Cycles: A Theoretical, Historical, and Statistical Analysis of the Capitalist Processes, Macmillan: New York, 1939. doi: http://dx.doi.org/10.1522/030021081

[5] Winner, L., Do artefacts have politics? Daedalus, 109(1), pp. 121-136, 1980.

[6] Porter, M.E. \& van der Linde, C., Green and competitive: ending the stalemate. Harvard Business Review, September-October, pp. 120-134, 1995.

[7] Hart, S.L., Beyond greening: strategies for a sustainable world. Harvard Business Review, January-February, pp. 66-76, 1997.

[8] Pehnt, M., Dynamic life cycle assessment (LCA) of renewable energy technologies. Renewable Energy, 31, pp. 55-71, 2006. doi: http://dx.doi.org/10.1016/j.renene.2005.03.002

[9] Owen, R., Bessant, J. \& Heingtz, M. (eds), Responsible Innovation: Managing the Responsible Emergence of Science and Innovation in Society, Wiley: Chichester, UK, 2013.

[10] Manders-Huits, N., What value in design? The challenge of incorporating moral values into design. Science and Engineering Ethics, 17, pp. 271-287, 2011. doi: http://dx.doi.org/10.1007/ s11948-010-9198-2

[11] Zerylnick, C., Torroni, A., Sherman, S.L. \& Warren, S.T., Normal variation at the myotonic dystrophy locus in global human populations. American Journal of Human Genetics, 56, pp. 123-130, 1995.

[12] Balkansky, A.K. \& Croissier, M.M., Multicrafting in prehispanic Oaxaca. Archeological Papers of the American Anthropological Association, 19(1), pp. 58-74, 2009. doi: http:// dx.doi.org/10.1111/j.1551-8248.2009.01013.x

[13] Jensen, M.E.R.G.N. \& van Broekhoven, L.N.K. (eds), Mixtec Writing and Society, Knaw Press: Amsterdam, 2008.

[14] Miles, L.D., Techniques of Value Analysis and Engineering, McGraw-Hill: USA, 1972.

[15] Santos-Reyes, D.E. \& Lawlor-Wright, T., Understanding design in nature can benefit product conceptual design. International Journal of Design \& Nature and Ecodynamics, 4(2), pp. 105-122, 2009. doi: http://dx.doi.org/10.2495/dne-v4-n2-105-122 